\title{
Continued emergence and changing epidemiology of oseltamivir-resistant influenza A(H1N1)2009 virus, United Kingdom, winter 2010/11
}

\author{
A Lackenby (angie.lackenby@hpa.org.uk) ${ }^{1}$, J Moran Gilad ${ }^{1}$, R Pebody $^{2}$, S Miah $^{1}$, L Calatayud ${ }^{2}$, S Bolotin $^{2}$, I Vipond B $^{3}$, P Muir ${ }^{3}$, \\ M Guiver ${ }^{4}$, J McMenamin 5 , A Reynolds ${ }^{5}$, C Moore ${ }^{6}$, R Gunson7, Cl Thompson², M Galiano², A Bermingham², J Ellis ${ }^{2}$, M Zambon $^{2}$ \\ 1. Health Protection Agency, Microbiology Services Colindale, London, United Kingdom \\ 2. Health Protection Agency, Health Protection Services Colindale, London, United Kingdom \\ 3. Health Protection Agency, Microbiology Services Bristol, United Kingdom \\ 4. Health Protection Agency, Microbiology Services Manchester, United Kingdom \\ 5. Health Protection Scotland, Glasgow, United Kingdom \\ 6. Public Health Wales Microbiology Cardiff, University Hospital of Wales, Cardiff, United Kingdom \\ 7. West of Scotland Specialist Virology Centre, Glasgow, United Kingdom
}

Citation style for this article:

Lackenby A, Moran Gilad J, Pebody R, Miah S, Calatayud L, Bolotin S, Vipond I, Muir P, Guiver M, McMenamin J, Reynolds A, Moore C, Gunson R, Thompson C, Lackenby A, Moran Gilad J, Pebody R, Miah S, Calatayud L, Bolotin S, Vipond I, Muir P, Guiver M, McMenamin J, Reynolds A, Moore C, Gunson R, Thompson C, Kingdom, winter 2010/11. Euro Surveill. 2011;16(5):pii=19784. Available online: http://www.eurosurveillance.org/ViewArticle.aspx?Articleld=19784

Article published on 3 February 2011

During the winter period 2010/11 27 epidemiologically unlinked, confirmed cases of oseltamivir-resistant influenza $A\left(\mathrm{H}_{1} \mathrm{~N}_{1}\right)_{2009}$ virus infection have been detected in multiple, geographically dispersed settings. Three of these cases were in community settings, with no known exposure to oseltamivir. This suggests possible onward transmission of resistant strains and could be an indication of a possibility of changing epidemiology of oseltamivir-resistant influenza $A\left(\mathrm{H}_{1} \mathrm{~N}_{1}\right) 2009$ virus.

To date, during the winter period 2010/11, 27 confirmed cases of oseltamivir-resistant influenza $\mathrm{A}\left(\mathrm{H}_{1} \mathrm{~N}_{1}\right)_{2009}$ virus infection have been detected. Three of these cases with resistant strains were in community settings. While the number of cases infected with a resistant strain who have been detected in the community is small, it is likely to have epidemiological significance given that no such cases were detected in 2009/10.

The 2010/11 winter season in the northern hemisphere has been characterised by co-circulation of different influenza strains, primarily influenza $A\left(\mathrm{H}_{1} \mathrm{~N}_{1}\right)_{2009}$, influenza $B$ and, sporadically, influenza $A\left(\mathrm{H}_{3} \mathrm{~N}_{2}\right)$ [1]. Residual population susceptibility to influenza $A\left(H_{1} N_{1}\right) 2009$ virus has led to severe and fatal illness among children and young adults, with many of the fatal cases having underlying risk factors associated with severe disease outcomes such as debilitating neurological conditions and chronic respiratory diseases. This emphasises the need for early antiviral therapy, which has proved successful in reducing viral shedding and severity of illness [2]. Neuraminidase inhibitors (NI) (oseltamivir and zanamivir), the most common antiviral drugs used for treatment and prophylaxis of patients with all influenza subtypes, were widely used in the first and second wave of the pandemic in the
United Kingdom (UK) during 2009, and were available through the National Pandemic Flu Service (NPFS) telephone helpline [3] to all sections of the population, irrespective of whether the patient belonged to a risk group. In the winter of 2010/11 the use of NI has been restricted to those in recognised clinical risk groups, consistent with National Institute for Health and Clinical Excellence (NICE) guidance [4].

Resistance to $\mathrm{NI}$ is determined by mutations in the viral neuraminidase (NA) [5]. During the first 10 years post licensure, oseltamivir resistance, when it was observed and investigated, was associated with a loss of viral fitness and reduction in transmissibility [6]. Mutations giving rise to $\mathrm{NI}$ resistance are both influenza subtypespecific and drug-specific, with a histidine to tyrosine mutation at position $275\left(\mathrm{H}_{275} \mathrm{Y}\right)$ of the viral NA being the most common in influenza $A\left(\mathrm{H}_{1} \mathrm{~N}_{1}\right)$ viruses [5]. Unexpectedly, during the winter season 2007/08, the emergence of a transmissible, drug-resistant influenza $A\left(\mathrm{H}_{1} \mathrm{~N}_{1}\right)$ strain rendered the use of oseltamivir ineffective against this subtype $[7,8]$. This strain, with $\mathrm{H} 275 \mathrm{Y}$ in the viral NA likely arose as a result of additional compensatory mutations elsewhere in the viral NA gene or elsewhere in the viral genome.

During the 2009 influenza $A\left(\mathrm{H}_{1} \mathrm{~N}_{1}\right)$ pandemic, oseltamivir was used extensively globally for both treatment and prophylaxis. A total of 319 cases infected with oseltamivir-resistant influenza viruses have been recognised globally, from more than 20,000 influenzapositive samples tested [9].

Resistance to oseltamivir was mainly detected in severely immunosuppressed individuals or hospitalised patients sampled post-treatment, although several clusters involving limited person-to-person 
transmission were recognised. While this indicated a low prevalence of oseltamivir resistance, the continual evolution of influenza viruses emphasises the necessity for close surveillance of antiviral resistance. Here we report on our findings during winter 2010/11.

\section{Methods}

Monitoring of antiviral drug susceptibility in the UK circulating influenza strains, among hospitalised and primary care patients, is performed as part of influenza virological strain surveillance and is integrated with antigenic and genetic analyses at the National Influenza Centre (NIC) at the Health Protection Agency (HPA), Colindale (Figure 1) [1]. Rapid genotypic screening of influenza $A\left(\mathrm{H}_{1} \mathrm{~N}_{1}\right) 2009$ strains for the $\mathrm{H}_{2} 75 \mathrm{Y}$ single-nucleotide polymorphism (SNP) by regional laboratories, beginning in England and Wales in October 2010 (and in Scotland in 2009), allows rapid detection of resistant strains closer to the point of care and supports a national enhanced surveillance programme for antiviral drug susceptibility. This screening is performed by SNP analysis on clinical specimens using a real-time polymerase chain reaction (PCR) method that differentiates between wild-type and resistant viruses. The HPA methodology is available on request, as the manuscript is in preparation. Resistance is confirmed by pyrosequencing at the NIC, where additional viral genotypic and phenotypic surveillance and characterisation is performed to identify additional alterations in drug susceptibility and any other associated mutations [10].

Clinically and epidemiologically relevant resistance ( $50 \%$ of viral quasi-species in the original clinical material harbour the $\mathrm{H}_{275} \mathrm{Y}$ mutation) are reported weekly in HPA weekly influenza reports, to the

\section{FIGURE 1}

Influenza A(H1N1)2009 antiviral drug testing strategy in the United Kingdom

Clinical specimen from hospital or community surveillance scheme

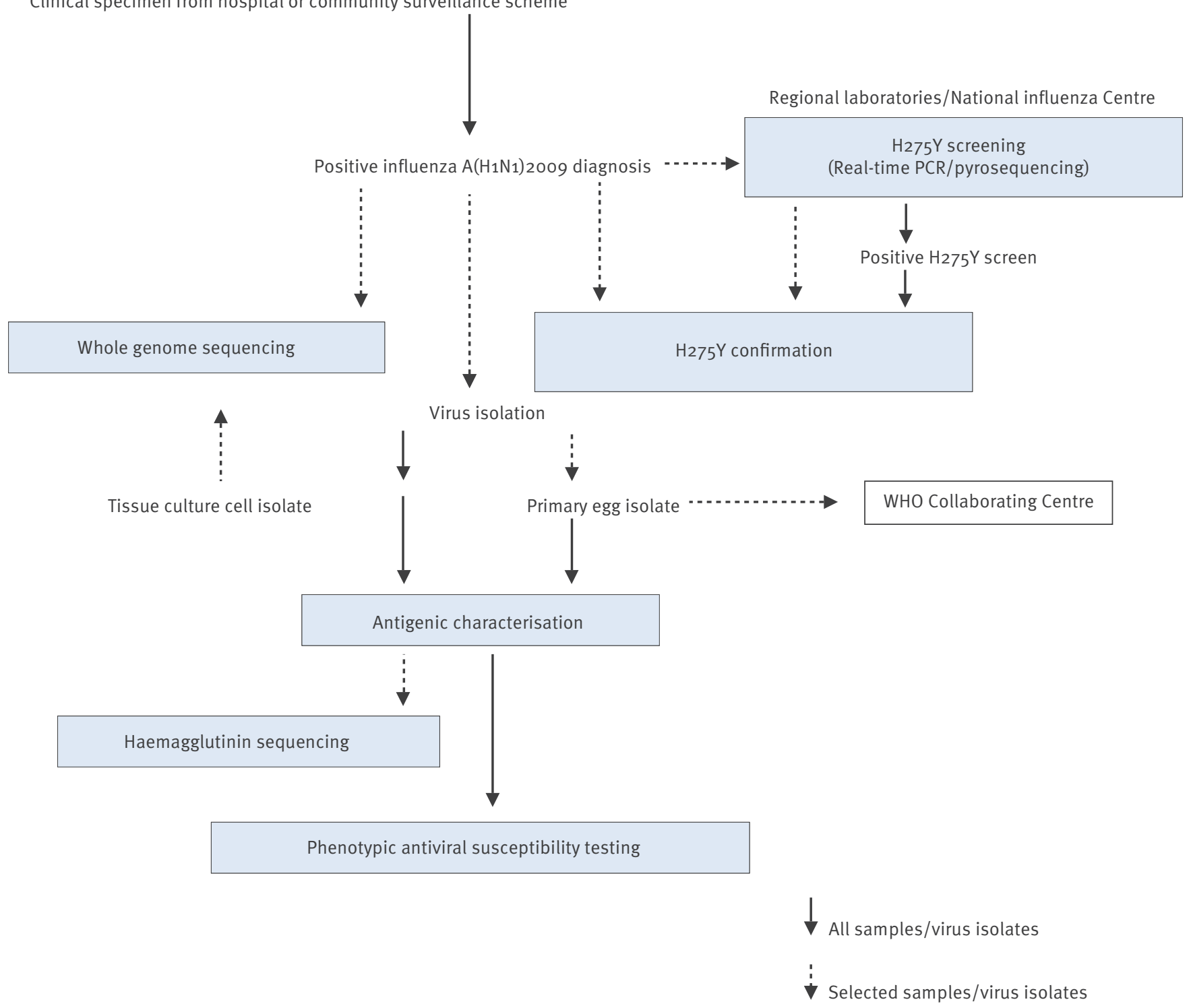

Source: Health Protection Agency, laboratories/National influenza Centre, United Kingdom. PCR: polymerase chain reaction; WHO: World Health Organization. 
European Centre for Disease Prevention and Control (ECDC) via the European Surveillance System (TESSy) and to the World Health Organization (WHO) headquarters and the WHO Regional Office for Europe. Clinical specimens with quasi-species harbouring $<50 \%$ resistant virus are reported back to clinicians as resistant for patient management but not internationally, according to the agreed WHO strategy (Technical consultation meeting (8 September 2010) proceedings paper under preparation by the WHO).

Written informed consent and explicit ethical approval was not sought as this was an observational study undertaken as part of routine pandemic surveillance. It was carried out under UK legislation NHS Act 2006 (section 251), which provides statutory support for disclosure of data by the NHS, and their processing by the Health Protection Agency (HPA) for communicable disease control. Health Protection Scotland remains a constituent part of the NHS and coordinates the investigation and management of all national outbreaks in Scotland. Additional clinical and laboratory data on influenza cases with resistant strains were collected via national databases and by contacting attending physicians where appropriate. Frequencies were compared using the chi-square or Fisher's exact test as appropriate.

\section{Virological findings}

To date, during the winter period 2010/11, 27 confirmed cases of oseltamivir-resistant influenza $\mathrm{A}\left(\mathrm{H}_{1} \mathrm{~N}_{1}\right) 2009$ virus infection have been detected up to week 3 of 2011 (Figure 2). Similar rates of oseltamivir resistance (1\%) due to the $\mathrm{H}_{275} \mathrm{Y}$ mutation were detected in 2010/11 as in 2009/10 (Table 1). During 2009/10, resistance was detected exclusively from hospital-based surveillance. However, three of 27 cases with resistant strains detected in $2010 / 11$ were in community settings, with no known exposure to oseltamivir $(p=0.05)$. While the number of cases infected with a resistant strain who have been detected in the community is small, it is likely to have epidemiological significance given that no such cases have been previously detected in 2009/10 despite a large sample size (1,098 cases analysed).

All oseltamivir-resistant viruses in $2010 / 11$ were wild type (isoleucine) at position 223 in NA, a site at which

\section{FIGURE 2}

Influenza-like illness consultation rates in primary care and cumulative cases infected with oseltamivir-resistant influenza A(H1N1)2009, United Kingdom, week 19 of 2009 to week 3 of 2011 [12]*
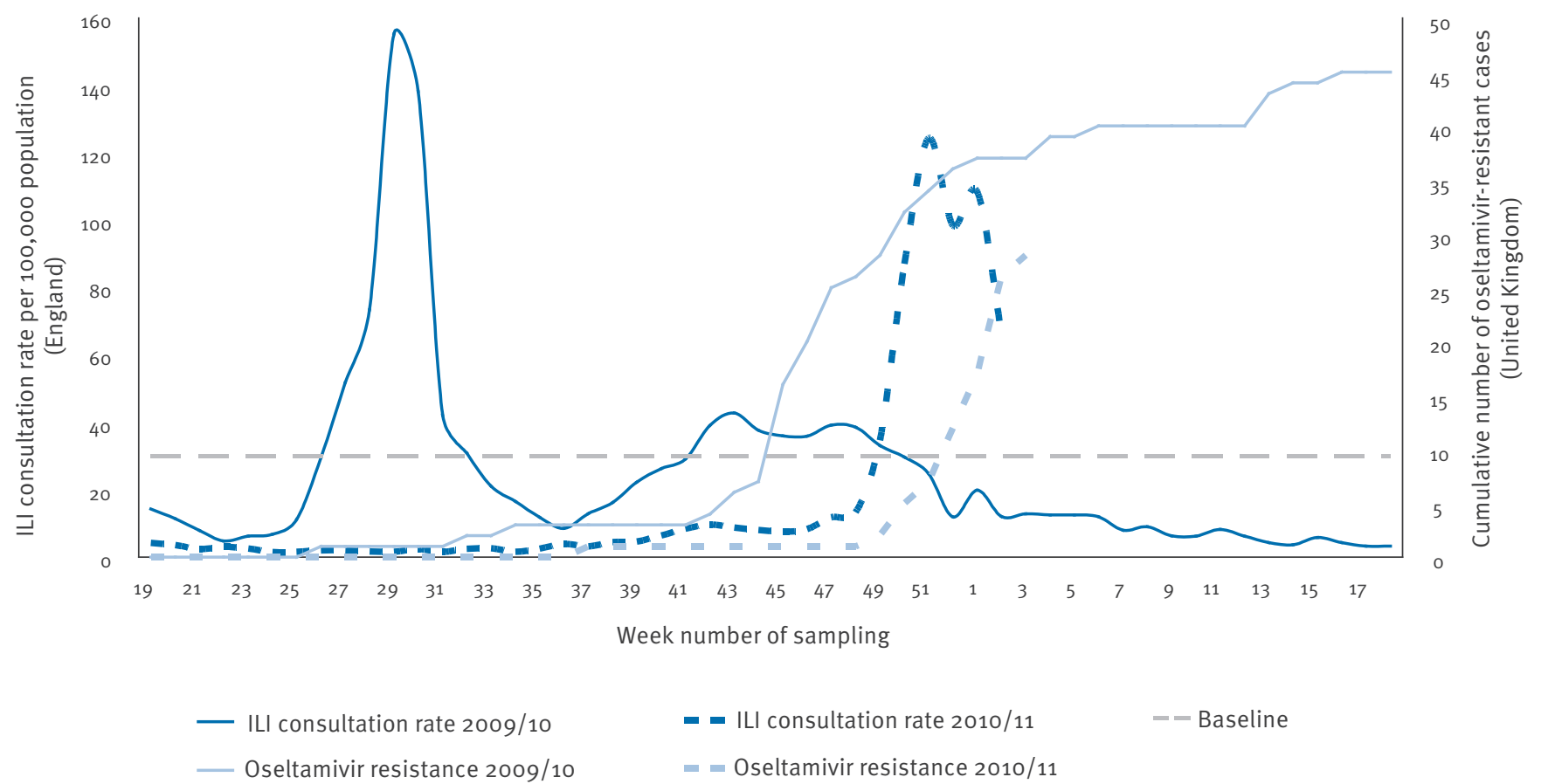

$$
\begin{aligned}
& \text { - } \text { - ILI consultation rate } 2010 / 11 \\
& =- \text { Oseltamivir resistance } 2010 / 11
\end{aligned}
$$$$
- \text { - Baseline }
$$

ILI: influenza-like illness.

\section{TABLE}

Incidence rates of oseltamivir-resistant influenza A(H1N1)2009 virus infection, United Kingdom, $2009 / 10$ (n=45) and 2010/11 ( $\mathrm{n}=27)$

\begin{tabular}{|l|c|c|c|c|c|c|}
\hline \multirow{2}{*}{ Setting } & \multicolumn{3}{|c|}{ May 2009-April 2010 } & \multicolumn{3}{c|}{ May 2010-January 2011 } \\
\cline { 2 - 8 } & Total tested & Number resistant & Percentage resistant & Total tested & Number resistant & Percentage resistant \\
\hline Community & 1,098 & 0 & 0.0 & 364 & 3 & 0.8 \\
\hline Hospital & 4,489 & 45 & 1.0 & 2,500 & 24 & 1.0 \\
\hline Total & 5,587 & 45 & 0.8 & 2,864 & 27 & 0.9 \\
\hline
\end{tabular}


mutations can increase the phenotypic impact of resistance due to the $\mathrm{H}_{275} \mathrm{Y}$ mutation.

Analysis of influenza $A\left(\mathrm{H}_{1} \mathrm{~N}_{1}\right) 2009$-positive material taken from both hospitalised and community cases during the first and second waves of the pandemic in the UK found that the earliest UK detection of oseltamivir resistance due to the $\mathrm{H}_{275} \mathrm{Y}$ mutation occurred in June 2009. A total of 45 resistant cases were detected between week 19 of 2009 and week 18 of 2010 (Figure

\section{FIGURE 3}

Patient characteristics associated with oseltamivirresistant influenza $\mathrm{A}(\mathrm{H} 1 \mathrm{~N} 1) 2009$ virus infection in the United Kingdom during 2009/10 ( $\mathrm{n}=44)$ and 2010/11 $(\mathrm{n}=24)$
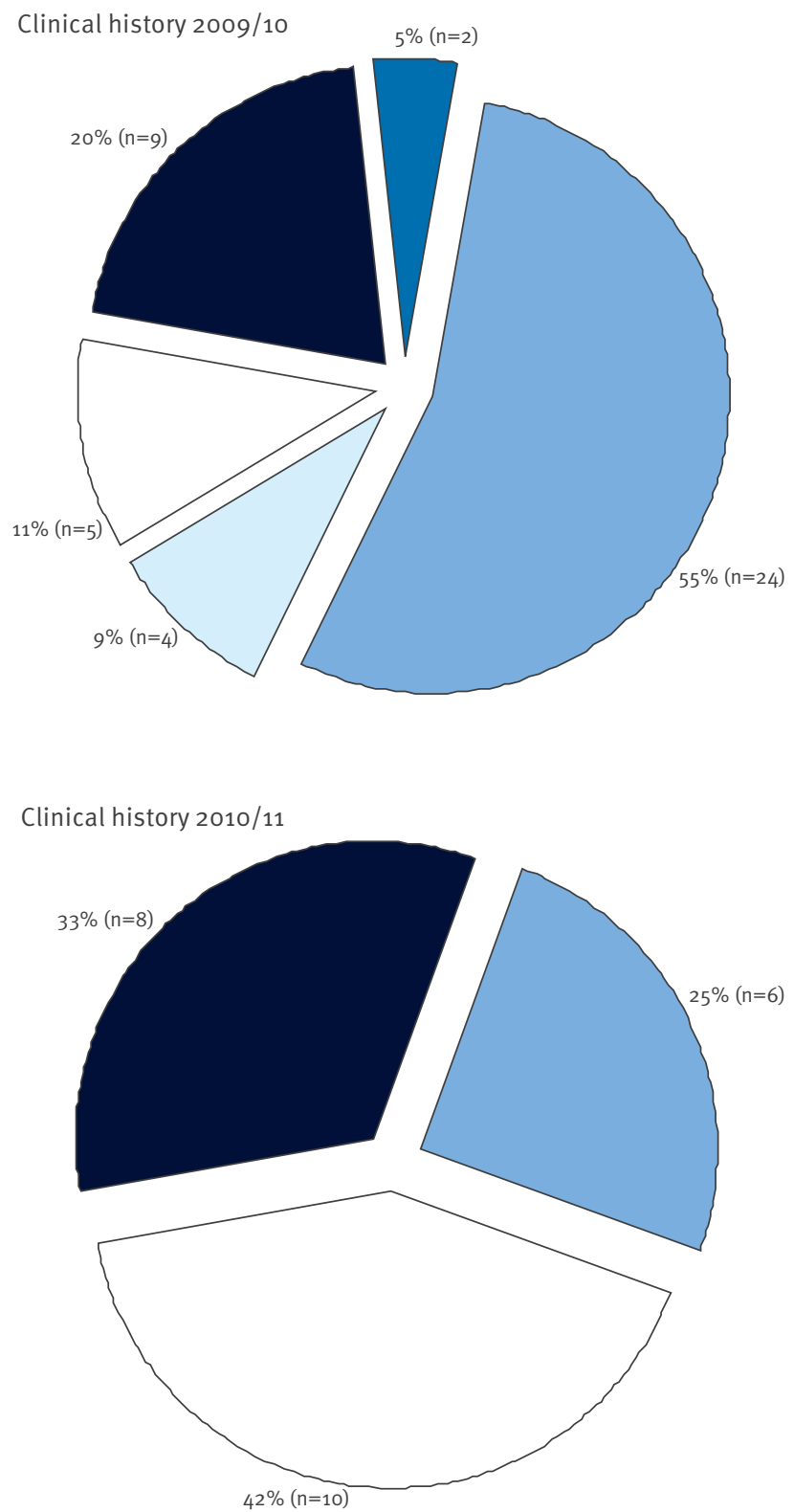

Associated with oseltamivir treatment

Oseltamivir post-exposure prophylaxis

$\square$ Severely immunocompromised (oseltamivir-treated)

$\square$ Transmission of oseltamivir resistant strain

$\square$ No known exposure to oseltamivir
2), eight of whom were associated with a nosocomial outbreak among severely immunocompromised individuals [11].

During 2009/10 the majority of sporadic resistance $(80 \%)$ was detected in individuals with a history of exposure to antiviral drugs or immunosuppression (Figure 3). Whole genome sequencing of 10 of 45 resistant strains and phenotypic analysis of 15 of 45 resistant strains did not reveal any other known drug-resistant variants.

\section{Clinical and epidemiological findings}

In $2010 / 11$, the mean age of all cases $(n=27)$ infected with oseltamivir-resistant influenza $A\left(\mathrm{H}_{1} \mathrm{~N}_{1}\right) 2009$ virus was 32 years (median: 37; range: nine months to 75 years); in 2009/10, the mean age of such cases $(n=45)$ was 38 years (median: 43 years; range: four months to 95 years). In 2010/11, 10 of the 27 cases were male and the corresponding figure for $2009 / 10$ was 33 of the 45 cases $(p=0.01)$.

Clinical and epidemiological features were available for 24 of 27 cases infected with oseltamivir-resistant influenza $A\left(\mathrm{H}_{1} \mathrm{~N}_{1}\right) 2009$ virus in $2010 / 11$ and 44 of 45 such cases in 2009/10 (Figure 3).

Most notably, 10 of 24 of cases with resistant strains in 2010/11 had no known exposure to oseltamivir or contact with known cases of resistance (including three otherwise healthy individuals sampled in the community as part of virological surveillance) as compared with five cases of 44 in 2009/10 $(p=0.01)$. The cases with resistant strains were distributed throughout England, Scotland and Wales. The frequency of these cases in both 2009/10 and 2010/11 increased with a 1-2-week delay (using sample date) of the increase in influenza-like illness (ILI) consultation rates (Figure 2), possibly reflecting that testing volume sufficient to detect infrequent resistance has been attained. ILI is defined as the presence of four of the following ICHPPC criteria i) sudden onset ii) cough iii) rigors/chills iv) fever v) prostration and weakness vi) myalgia vii) no significant respiratory physical signs other than redness of nasal mucous membrane and throat viii) influenza in a close contact.

Seven patients (of 24) in 2010/11 were immunosuppressed (six were treated with oseltamivir and one had no known oseltamivir exposure), compared with 34 of 44 immunosuppressed patients in 2009/10 ( $p=0.001)$. Of the $2009 / 10$ cases, 24 were treated, two were given post-exposure prophylaxis, four were infected with the resistant strain and four had no known exposure to oseltamivir in 2010/11. To date in 2010/11, there has been no documented onward transmission of resistant strains, whereas in 2009/10, transmission was documented for four of 44 cases with resistant strains $(p=0.3)$. 


\section{Conclusions}

In 2010/11, cases infected with oseltamivir-resistant influenza $A\left(\mathrm{H}_{1} \mathrm{~N}_{1}\right)_{2009}$ virus have emerged sporadically in the community, some of whom have had no known exposure to oseltamivir, in addition to such cases occurring in hospitalised patients. Although clustering has not been formally ascertained, it is considered unlikely, which therefore suggests the likelihood of low-level onward transmission of resistant strains. In 2007/8 oseltamivir-resistant seasonal influenza $\mathrm{A}\left(\mathrm{H}_{1} \mathrm{~N}_{1}\right)$ harbouring the $\mathrm{H}_{2} 75 \mathrm{Y}$ mutation emerged, unrelated to antiviral drug use, and spread at varying rates globally, quickly becoming dominant over the sensitive strain in most countries by the end of 2008 [13]. The emergence of oseltamivir-resistant influenza $\mathrm{A}\left(\mathrm{H}_{1} \mathrm{~N}_{1}\right) 2009$ virus is of concern and, despite the current low levels, requires vigilance.

The frequency of immunosuppression as an underlying risk factor is lower among cases with resistant strains in $2010 / 11$, which may be explained in part by the high index of suspicion for the emergence of resistance due to the $\mathrm{H}_{275} \mathrm{Y}$ mutation, resulting in increased and timely use of zanamivir in this patient population, as advocated by national UK guidance. The HPA revised guidance for managing influenza in the era of emerging oseltamivir resistance emphasises the necessity of active surveillance for antiviral drug resistance, particularly among high-risk groups such as those who are immunosuppressed $[14,15]$.

In the light of the varying rates of oseltamivir resistance among different influenza subtypes and across geographical locales, the choice of antiviral agent is often difficult. Clinical decisions should therefore be based on the perceived risk for resistance both at the individual level and global (population) level, using current local virological and epidemiological data wherever possible. A proposed model for such risk assessment is outlined in Figure 4. Ongoing incidence of oseltamivir resistance in the community in patients without evident risk factors will influence antiviral prescribing recommendations if the overall frequency of resistance rises above $10 \%$. Decisions about antiviral therapy for patient management will increasingly require risk assessment and national and international antiviral policies.

Observational data produced through surveillance provide the crude rates of oseltamivir resistance among currently circulating influenza subtypes. Assessing risk factors for antiviral resistance and propensity for onward transmission are also important and assist in recognition of new resistance mechanisms. Current in vitro and in vivo studies of the fitness of resistant influenza $A\left(\mathrm{H}_{1} \mathrm{~N}_{1}\right) 2009$ strains are conflicting. In human airway cultures the resistant variant was shown to have a fitness deficit in comparison to its wild-type counterpart [16] and Duan et al. found that the drug resistant virus only transmitted via the contact route, not the respiratory droplet route and was outgrown by its wildtype counterpart in co-infected animals [17]. In contrast however, Hamelin et al. found that oseltamivir-resistant $\mathrm{A}\left(\mathrm{H}_{1} \mathrm{~N}_{1}\right)$ virus was equally virulent as its wild-type counterpart in mice and ferrets and did transmit [18].

\section{FIGURE 4}

A decision-support tool for guiding the choice of antivirals through risk assessment ${ }^{\mathrm{a}}$

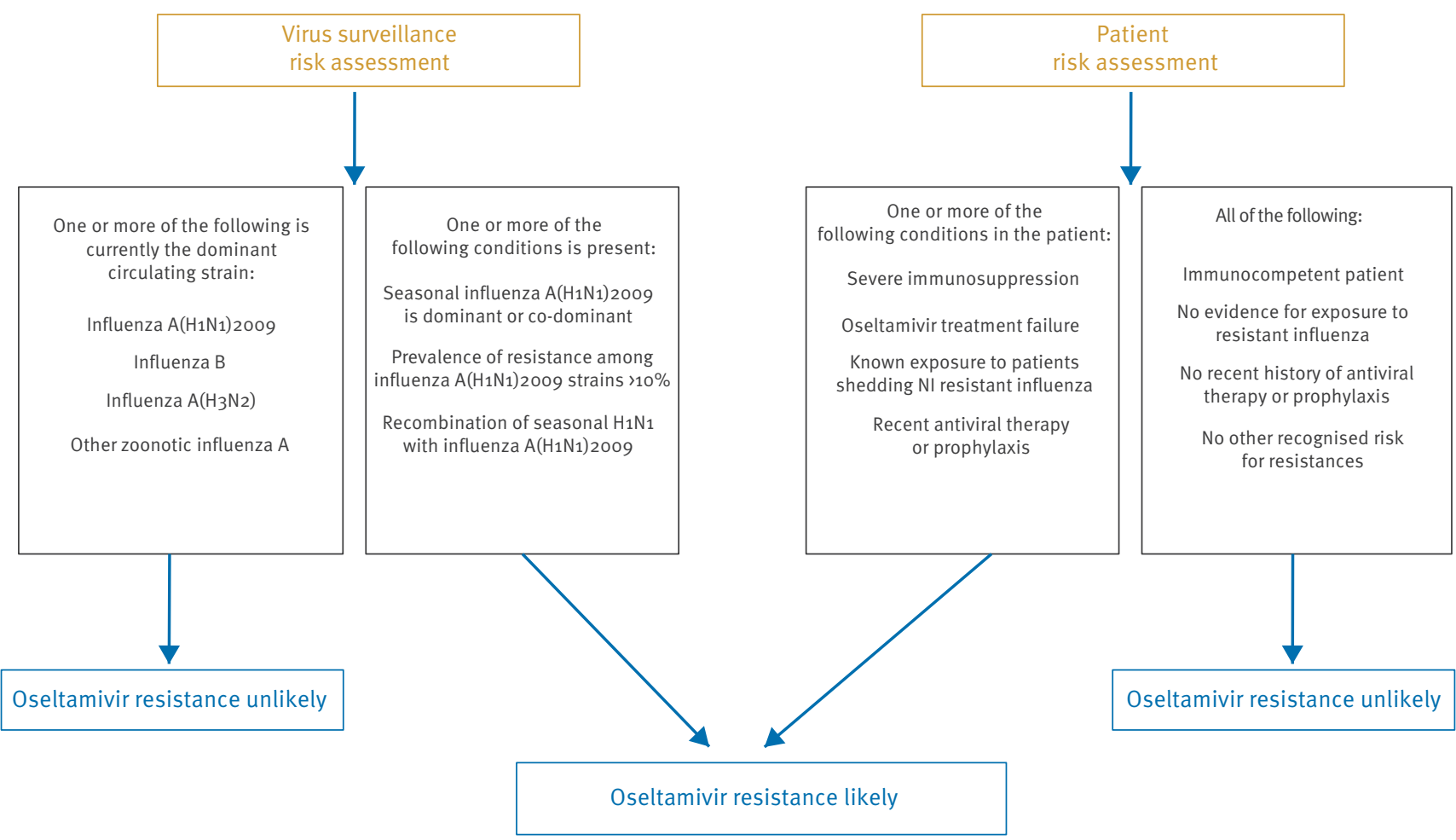

a For patients requiring prophylaxis or antiviral therapy for suspected or proven influenza $A\left(\mathrm{H}_{1} \mathrm{~N}_{1}\right) 2009$ 
Our surveillance findings imply the need for urgent studies to evaluate possible underlying compensatory mutations among resistant strains.

\section{Acknowledgements}

The authors would like to acknowledge the contribution of the member laboratories of the Microbiology Services Division Laboratory Network, HPA, for H275Y SNP surveillance and submitting clinical samples evaluated in this study. We also wish to acknowledge the participating Royal College of General Practitioners (RCGP) practices for submitting clinical samples. Technical and data support was provided by the Respiratory Virus Unit, Microbiology Services Colindale, with particular thanks to Claudia Rosenow, Sammy Ho, Praveen SebastianPillai and Kate Howell and Hongxin Zhao, Health Protection Services Colindale.

* Erratum: The title of Figure 2 was corrected after publication of the article, on 4 February 2011

\section{References}

1. Ellis J, Galiano M, Pebody R, Lackenby A, Thompson C, Bermingham A, McLean E, Zhao H, Bolotin S, Dar O, Watson $J M$, Zambon M. Virological analysis of fatal influenza cases in the United Kingdom during the early wave of influenza in winter 2010/11. Euro Surveill. 2011;16(1): pii=19760. Available from: http://www.eurosurveillance.org/ViewArticle. aspx?Articleld $=19760$

2. Moscona A. Neuraminidase inhibitors for influenza. N Engl Med. 2005;353(13):1363-73.

3. McLean E, Pebody R, Chamberland M, Paterson B, Smyth B, Kearns C et al. Epidemiological report of pandemic (H1N1) 2009 in the UK. Health Protection Agency. Available from: http:// www.hpa.org.uk/web/HPAwebFile/HPAweb_C/1284475321350.

4. National Health Service (NHS). National Institute for Health and Clinical Excellence.[Internet]. Influenza - zanamir, amantadine and oseltamivir (review). Amantadine, oseltamivir and zanamivir for the treatment of influenza: review of NICE technology appraisal guidance 58. February 2009. [Accessed 17 January]. Available from: http://guidance.nice.org.uk/TA168

5. McKimm-Breschkin JL. Resistance of influenza viruses to neuraminidase inhibitors--a review. Antiviral Res. 2000;47(1):1-17.

6. Ives JA, Carr JA, Mendel DB, Tai CY, Lambkin R, Kelly L, et al. The $\mathrm{H}_{274} \mathrm{Y}$ mutation in the influenza $\mathrm{A} / \mathrm{H}_{1} \mathrm{~N}_{1}$ neuraminidase active site following oseltamivir phosphate treatment leave virus severely compromised both in vitro and in vivo. Antiviral Res. 2002;55(2):307-17.

7. Lackenby A, Hungnes O, Dudman SG, Meijer A, Paget WJ, Hay AJ, Zambon MC. Emergence of resistance to oseltamivir among influenza $A\left(\mathrm{H}_{1} \mathrm{~N}_{1}\right)$ viruses in Europe. Euro Surveill. 2008;13(5):pii=8026. Available from: http://www. eurosurveillance.org/ViewArticle.aspx?Articleld=8026

8. Sheu TG, Deyde VM, Okomo-Adhiambo M, Garten R, Xu X, Bright $R$, et al. Surveillance for neuraminidase inhibitor resistance among human influenza $A$ and $B$ viruses circulating worldwide from 2004 to 2008 . Antimicrob Agents Chemother. 2008;52(9):3284-92.

9. World Health Organization. [Internet]. Weekly update on oseltamivir resistance to influenza $\mathrm{H}_{1} \mathrm{~N}_{1}$ (2009) viruses, WHO 14 January 2011, [Accessed 17 January]. Available from: http:// www.who.int/csr/disease/influenza/2011_01_12_weekly_web update_oseltamivir_resistance.pdf

10. Lackenby A, Democratis I, Siqueira MM, Zambon MC. Rapid quantitation of neuraminidase inhibitor drug resistance in influenza virus quasispecies. Antivir Ther. 2008;13(6):809-20.

11. Moore C, Galiano M, Lackenby A, Abdelrahman T, Barnes R, Evans MR, et al. Evidence of person-to-person transmission of oseltamivir resistant pandemic influenza $A\left(\mathrm{H}_{1} \mathrm{~N}_{1}\right) 2009$ virus in a hematology unit. Journal of Infectious Diseases 2010; J Infect Dis. 2011;203(1):18-24.

12. Goddard NL, Kyncl J, Watson JM Appropriateness of thresholds currently used to describe influenza activity in England. Commun Dis Public Health. 2003;6(3):238-45.
13. Meijer A, Lackenby A, Hungnes O, Lina B, van-der-Werf $\mathrm{S}$, Schweiger B, et al. Oseltamivir-resistant influenza virus $A\left(\mathrm{H}_{1} \mathrm{~N}_{1}\right)$, Europe, 2007-08 season. Emerg Infect Dis. 2009;15(4):552-60.

14. Health Protection Agency. [Internet]. HPA policy on influenza antiviral susceptibility surveillance and laboratory diagnosis of resistance: 2010-11, United Kingdom. Version 1.5, January 2011. Available from: http://www.hpa.org.uk/web/HPAwebFile/ HPAweb_C/1287147818576

15. Health Protection Agency. Pharmacological treatment and prophylaxis of influenza. Version 1.7, January 2011. Available from: http://www.hpa.org.uk/web/HPAwebFile/ HPAweb_C/1287147812045

16. Brookes DW, Miah S, Lackenby A, Hartgroves L, Barclay WS. Pandemic $\mathrm{H}_{1} \mathrm{~N}_{1} 2009$ influenza virus with the $\mathrm{H}_{2} 25 \mathrm{Y}$ oseltamivir resistance neuraminidase mutation shows a small compromise in enzyme activity and viral fitness. J Antimicrob Chemother. 2010 Dec 16. [Epub ahead of print]

17. Duan S, Boltz DA, Seiler P, Li J, Bragstad K, Nielsen LP et al. Oseltamivir-resistant pandemic $\mathrm{H}_{1} \mathrm{~N}_{1} / 2009$ influenza virus possesses lower transmissibility and fitness in ferrets. PLoS Pathog. 2010;6(7)

18. Hamelin ME, Baz M, Abed Y, Couture C, Joubert P, Beaulieu E et al. Oseltamivir-resistant pandemic $A / \mathrm{H}_{1} \mathrm{~N}_{1}$ virus is as virulent as its wild-type counterpart in mice and ferrets. PLoS Pathog. 2010;6(7) 